\title{
Oxygen Reduction Reaction (ORR) on Platinum Coated Nafion Membrane: Effects of Synthesis Conditions
}

\author{
Sakineh Chabi ${ }^{*}$, Mehdi Kheirmand ${ }^{2}$ \\ ${ }^{1}$ Renewable Energy Department, Research Institute of Petroleum Industry (RIPI), Tehran, Iran \\ ${ }^{2}$ Department of Chemistry, School of Science, Yasouj University, Yasouj, Iran \\ Email: *sc548@exeter.ac.
}

Received 7 January 2016; accepted 23 January 2016; published 27 January 2016

Copyright (C) 2016 by authors and OALib.

This work is licensed under the Creative Commons Attribution International License (CC BY). http://creativecommons.org/licenses/by/4.0/

c) (†) Open Access

\section{Abstract}

The present study describes the catalytic activity of the platinum coated Nafion membranes towards oxygen reduction reaction in proton exchange membrane fuel cells. In contrast to the conventional three layered structures of the gas diffusion electrode, as-made gas diffusion electrodes are two layered in which the platinum electrocatalyst are deposited directly onto the Nafion membrane. Spin-coating method and impregnation-reduction approaches were used to synthesize Pt-coated Nafion membranes. Both methods showed comparable results. The performance data revealed that the catalytic activity of the Nafion-Pt-GDL electrode was strongly affected by the Nafion treatment and platinum crystal structures. The results suggest that spin-coated method is a very successful technique for producing low loading of platinum electrocatalyst. Not only platinum catalyst, but also a wide arrange of catalyst-coated Nafion membranes such as palladium/Nafion can be prepared by this approach.

\section{Keywords}

Spin Coating, Nafion Membrane, Electrocatalyst, Oxygen Reduction Reaction, Fuel Cell

Subject Areas: Analytical Chemistry, Electrochemistry

\section{Introduction}

Proton exchange membrane (PEM) fuel cells are considered to be one of the most promising energy sources devices due to a combination of effects, e.g. renewability, low pollution emission, portability, high energy density, high energy conversion efficiency, low noise, and relatively simple design and quick start up [1]-[6].

${ }^{*}$ Corresponding author.

How to cite this paper: Chabi, S. and Kheirmand, M. (2016) Oxygen Reduction Reaction (ORR) on Platinum Coated Nafion Membrane: Effects of Synthesis Conditions. Open Access Library Journal, 3: e2125.

http://dx.doi.org/10.4236/oalib.1102125 
PEM fuel cells have been employed successfully for a wide range of applications including transportation devices, as PEM fuel cell technology has already powered many vehicles such as fuel cell cars. Nevertheless, the commercialization of these systems still presents some technical challenges. The first problem is the high cost of a platinum catalyst. And the second problem is the slow kinetic of ORR at the cathode electrode. And in this regard, the architecture and nanostructure of the membrane electrode assembly (MEA) plays an important role in overcoming these challenges.

As the heart of a PEM fuel cell, the MEA unit consists of two individual gas diffusion electrodes (GDEs) and a solid membrane electrolyte. A conventional GDE has a three layered structure: a support layer (carbon paper or carbon cloth), a gas diffusion layer and a catalyst layer. So far, these types of GDEs and MEA architectures have not led to the industrialization of the PEM fuel cells and also have not addressed the low activity of the ORR reaction. Therefore, new architectures need to be developed. Indeed, there are many concerns associated with the traditional design of the GDE. Poor contact between the catalyst layer and the Nafion membrane, low catalyst utilization, catalyst layer degradation and balance problems between proton and electron conductivity are typical problems with the current architecture [7]-[11].

In order to address these challenges, a number of approaches have been studied. One of these techniques is the direct deposition of the catalyst onto the Nafion membrane. Introducing platinum particles onto the electrolyte affects positively the durability, humidity and conductivity of the Nafion membrane. Catalyst-coated electrolyte (the Nafion membrane in this context) provides separated paths for hydrophobic and hydrophilic phases and the results in a better utilization of the platinum catalyst [11]-[13].

Several techniques have been used to deposit a catalyst onto Nafion membrane, e.g. mechanically pressing, chemical reduction, electrochemical deposition, impregnation-reduction method and plasma sputtering technique [7] [14]-[22].

In our previous work [23] we prepared Pt-coated Nafion membranes chemically by using Chloroplatinic acid and sodium format as a platinum source and reducing agent respectively. In this work, we improved the efficiency of the Pt/Nafion/GDL electrode significantly by optimizing preparation conditions and changing the reducing agent. The performance data revealed eighteen times as much improvement as compared with the previous work. Further to this, we have also used a spin-coating method to synthesis the Pt/Nafion/GDL electrode. This approach is completely novel, and has not been reported elsewhere. Spin coating, is an easy and fast method for producing uniform thin films. This method has been used for synthesizing electrolyte layers for solid oxide fuel cell and also for solar energy applications [24]. The thickness of the deposited layer is highly affected by deposition conditions, including rotation rate and deposition time. To obtain a thicker catalyst layer, high viscosity, low rotation speed and low deposition time are required [25].

\section{Experimental}

\subsection{Electrode Preparation}

Impregnation-reduction and spin-coated methods were used to prepare platinum-coated Nafion membranes. Chemically-prepared samples were fabricated as described in [23]. However, different preparation conditions and a different reducing agent were employed in this work. $\mathrm{H}_{2} \mathrm{PtCl}_{6}$ (40\%, Merck) and $0.1 \mathrm{M} \mathrm{NaBH}_{4}-1 \mathrm{M} \mathrm{NaOH}$ were used as platinum precursor and reducing agent respectively. In a brief, modified Nafion membranes (Aldrich) were first placed in platinum salt solution $\left(60^{\circ} \mathrm{C}\right)$, and then sodium borohydride was dropped as a reducing agent. The volume ratio of $\mathrm{NaBH}_{4}-\mathrm{NaOH}$ to $\mathrm{H}_{2} \mathrm{PtCl}_{6}$ was 2:1. Platinum metals were formed on the Nafion Membrane surface according to the following reactions.

$$
\begin{gathered}
\mathrm{PtCl}_{6}^{-}+4 \mathrm{e}^{-} \rightarrow \mathrm{Pt}+6 \mathrm{Cl}^{-} \\
\mathrm{BH}_{4}^{-}+3 \mathrm{H}_{2} \mathrm{O}-4 \mathrm{e}^{-} \rightarrow \mathrm{BO}_{3}^{3-}+2 \mathrm{H}_{2}+6 \mathrm{H}^{+} \\
\mathrm{PtCl}_{6}^{2-}+\mathrm{BH}_{4}^{-}+3 \mathrm{H}_{2} \mathrm{O} \rightarrow \mathrm{Pt}+\mathrm{BO}_{3}^{3-}+6 \mathrm{Cl}^{-}+2 \mathrm{H}_{2}+6 \mathrm{H}^{+}
\end{gathered}
$$

At the end of the platinum deposition, the catalyzed Nafion membranes were washed with deionized water several times to eliminate excess $\mathrm{NaBH}_{4}$ ions. After this, the Pt/Nafion 117 membrane was exchanged to $\mathrm{H}^{+}$form with $1 \mathrm{M} \mathrm{H}_{2} \mathrm{SO}_{4}$ prior to drying for weighing [26]-[29].

Table 1 summarizes the preparation conditions of GDEs. The physical synthesis was carried out using a spin 
Table 1. Preparation conditions of the GDEs.

\begin{tabular}{|c|c|c|c|}
\hline Sample & {$\left[\mathrm{H}_{2} \mathrm{PtCl}_{6}\right] / \mathrm{M}$} & Platinum deposition method & Heating details \\
\hline GDE1 & 0.05 & chemically & $60^{\circ} \mathrm{C}$, hot plate, 10 min impregnation-reduction process \\
\hline GDE2 & 0.08 & chemically & $60^{\circ} \mathrm{C}$, hot plate, 10 min impregnation-reduction process \\
\hline GDE3 & 0.01 & Chemically & $60^{\circ} \mathrm{C}$, hot plate, 30 min impregnation-reduction process \\
\hline GDE4 & 0.005 & Chemically & $60^{\circ} \mathrm{C}$, hot plate, 30 min impregnation-reduction process \\
\hline GDE5 & 0.02 & chemically & $\begin{array}{l}50^{\circ} \mathrm{C}-60^{\circ} \mathrm{C} \text {, hot plate, } 30 \mathrm{~min} \\
\text { impregnation-reduction process }\end{array}$ \\
\hline GDE6 & 0.04 & Spin-coating & $\begin{array}{l}\text { Heating in oven }\left(75^{\circ} \mathrm{C}\right) \text {, after any rotation } \\
\text { process and deposition, }\end{array}$ \\
\hline GDE7 & 0.01 & Spin-coating & Noheating \\
\hline GDE8 & 0.01 & Spin-coating & Heating in oven $\left(75^{\circ} \mathrm{C}\right)$, after 3 times deposition process \\
\hline GDE9 & 0.04 & Spin-coating & Heating in oven, after three times deposition process \\
\hline
\end{tabular}

coater system, model KW-4A. The Pt/Nafion preparation in this method was a three steps procedure: First, platinum metals were prepared by the electroless method from the platinum salt precursor $\left(\mathrm{H}_{2} \mathrm{PtCl}_{6}\right)$, then after placing Nafion membrane on the spin coater and setting rotation time and speed, platinum solution was injected into the Nafion membrane using a micropipette. The resulting platinum-coated Nafion membranes were dried in an oven at $70^{\circ} \mathrm{C}$. The rotation speed was ca. $2000 \mathrm{rpm}$. Gas diffusion electrodes (GDEs), were prepared by hot pressing the Pt-Nafion membranes onto the gas diffusion layer [23].

\subsection{Measurements}

The structure and elemental composition of the GDEs were investigated by scanning electron microscopy (SEM), $\mathrm{X}$-ray diffraction (XRD) and energy-dispersive X-ray spectrometer (EDAX). The electrochemical behavior of the as-made electrodes was analyzed by electrochemical impedance spectroscopy (EIS), linear sweep voltammetry (LSV) and cyclic voltammetry (CV) measurement in $2 \mathrm{M} \mathrm{H}_{2} \mathrm{SO}_{4}$. LSV and EIS measurements were carried out in the presence of $\mathrm{O}_{2}$. Cyclic voltammetry experiment was performed in the presence of $\mathrm{N}_{2}$.

The LSV data were recorded at the scan rate of $5 \mathrm{mV} \cdot \mathrm{s}^{-1}$. For CV tests the scan rate was $40 \mathrm{mV} \cdot \mathrm{s}^{-1}$. Impedance experiments were carried out at potential of $0.3 \mathrm{~V}$ in the frequency range of $100 \mathrm{~K} \cdot \mathrm{Hz}$ to $0.1 \mathrm{~Hz}$. A potentiostatgalvanostatic (Zahner ${ }^{\circledR}$ ) instrument and a three electrode cell with an Ag/AgCl reference electrode and a $\mathrm{Pt}$ counter electrode were used to perform the electrochemical tests.

\section{Results and Discussion}

The electrocatalytic activity of the new GDEs (Nafion-Pt/GDL) towards oxygen reduction reaction (ORR) was assessed by LSV test. Figure 1(a) shows the LSV curves of chemically synthesized electrodes.

As shown, GDE3 has higher current densities and lower over potential than other electrodes. Both GDE1 and GDE4 exhibit almost the same performance, though they have different platinum loading. As for lower loading of platinum (GDE4) there is less active site for ORR and at higher loading (GDE1) there is the possibility of mass polarization, thus it is necessary to have optimized platinum loading. Compared with other electrodes, GDE3 shows higher current density, lower over potential and hence a better activity towards ORR. At lower current density, the current is restricted by reaction kinetics whereas at a higher current density, the current is limited by reactants diffusion [30] [31].

The LSV curves of physically prepared electrodes are presented in Figure 1(b). Here, GDL6 shows a much higher current density and lower over potential than other electrodes. The oxygen reduction reaction for this electrode occurs in a more positive potential than that of the other electrodes. The improved performance of GDE3 and GDE6 relates directly to the preparation conditions and morphology characteristics of the electrodes.

The kinetics data of the as-made GDEs were obtained using the Tafel equation and polarization data [32]. Table 2 lists the Tafel slopes and exchange current densities of the GDEs. As listed, GDE3 has a lower Tafel slope than other electrodes. Platinum loading of this electrode was $0.15 \mathrm{mg} \cdot \mathrm{cm}^{-2}$. Higher concentration leads to a higher 


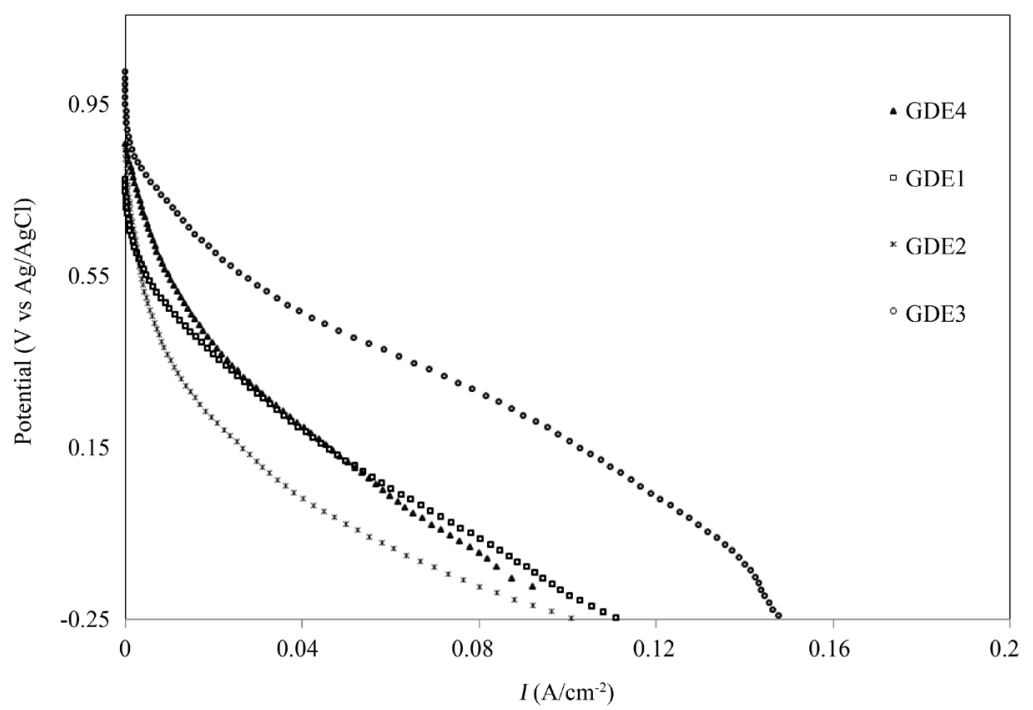

(a)

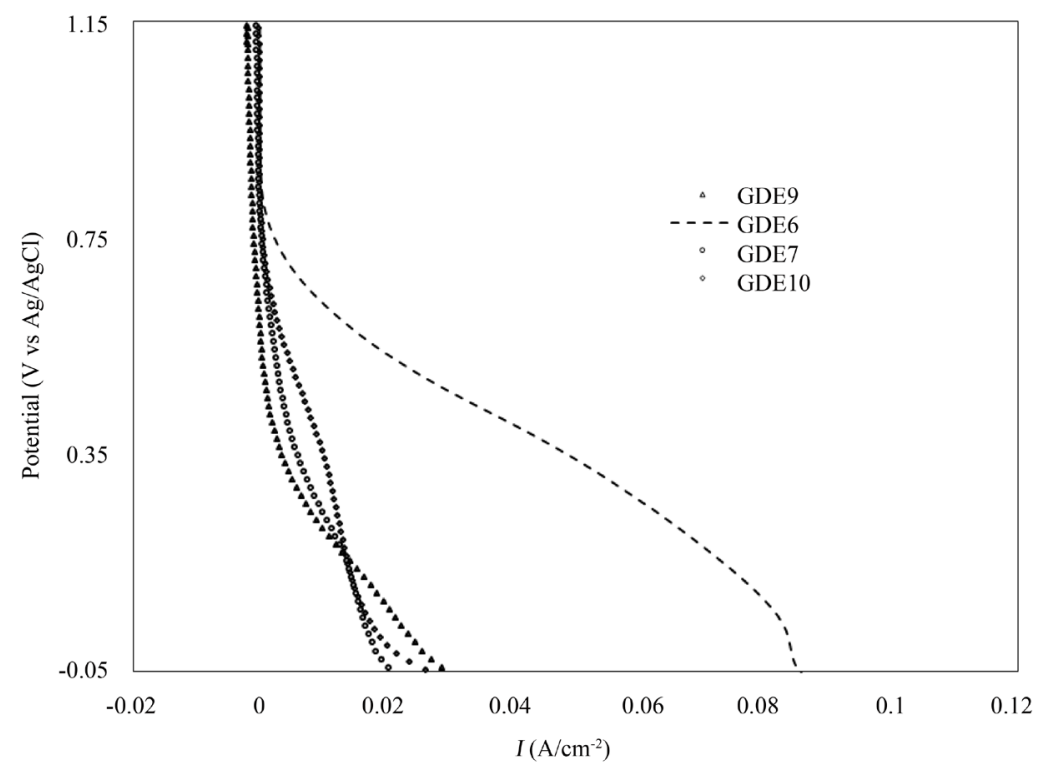

(b)

Figure 1. Potential vs. current density curves of different electrodes.

Table 2. Tafel slopes and exchange current densities of the GDEs.

\begin{tabular}{ccc}
\hline Sample & $i_{0}\left(\mathrm{~m} \cdot \mathrm{A} \cdot \mathrm{cm}^{-2}\right)$ & $b\left(\mathrm{~m} \cdot \mathrm{V} \cdot \mathrm{dec}^{-1}\right)$ \\
\hline GDE1 & $4.9 \times 10^{-5}$ & 114 \\
GDE2 & $5.5 \times 10^{-5}$ & 112 \\
GDE3 & $3.02 \times 10^{-4}$ & 91 \\
GDE4 & $8.1 \times 10^{-5}$ & 105 \\
GDE5 & $9.8 \times 10^{-5}$ & 107 \\
GDE6 & $3.00 \times 10^{-4}$ & 93 \\
GDE7 & $2.80 \times 10^{-5}$ & 101 \\
GDE8 & $2.60 \times 10^{-5}$ & 103 \\
GDE9 & $4.00 \times 10^{-5}$ & 100 \\
\hline
\end{tabular}


loading but not necessarily a better performance because of mass transfer problems. For spin-coated samples, GDE6 demonstrates a better polarization plot, and better kinetics data than other electrodes. This electrode has the same loading as GDE 3 . The Tafel slope of this electrode is $93 \mathrm{mV} / \mathrm{dec}$ and the exchange current density is $3 \times$ $10^{-4} \mathrm{~A} \cdot \mathrm{cm}^{-2}$. These electrochemical parameters are close to the kinetic parameters of the GDE3.

Figure 2 shows cyclic voltammetry (CV) curve of the GDE3. With the scanning of potential, ions move towards the surface to form a double-layer. Hydrogen adsorption and hydrogen desorption are evident as peaks in the CV plot [33]. As shown, the hydrogen desorption peaks are formed in the lower potentials $(<0.3 \mathrm{~V})$. Columbic charge of the hydrogen desorption peak was used to calculate the active surface area (S) of the electrode [34]. The electrochemical active surface area of the electrode was calculated to be $61 \mathrm{~m}^{2} \cdot \mathrm{g}^{-1}$.

ORR activities of the electrodes were further investigated using electrochemical impedance spectrometry (EIS), in the presence of $\mathrm{O}_{2}$. It is worth noting that the Nafion membrane it-self has a resistance of about $10 \Omega$ [35]. Figure 3 illustrates the impedance results of different electrodes.

As shown, the Nyquist plot of each electrode takes the form of a single semi-circular curve at high frequencies which is related to charge transfer resistance at the electrode (Nafion/Pt/GDL) electrolyte interface. For chemically prepared electrodes (Figure 3(a)), GDE3 possesses a lower semi-circle diameter revealing a faster faradic reaction. The charge transfer resistance $\left(\mathrm{R}_{\mathrm{ct}}\right)$ of this electrode is $8 \Omega$. This electrode also showed higher OCP (open circuit potential) than other electrodes. $\mathrm{R}_{\mathrm{ct}}$ values of GDE1 and GDE2 are 9 and $11 \Omega$ respectively.

For spin-coated samples (Figure 3(b)), GDE6 shows the best Nyquist curve among all electrodes. This electrode has the lowest charge transfer resistance, which is $6 \Omega$.

The equivalent circuit for semi-circle Nyquist curves is illustrated in Figure 3(c). Where, $\mathrm{R}_{\mathrm{S}}$ is the solution resistance of the electrochemical system, $\mathrm{R}_{\mathrm{ct}}$ is the charge transfer resistance and CPE is the constant phase element. The observed total impedance is a combination of resistance and capacitance at each applied frequency. By reading real axis value at the high frequency intercept, resistance solution has been found to be about $2 \Omega$.

The improved activity of the GDE3 and GDE6 is related directly to their preparation condition. These electrochemical results suggest that Nafion treatment, low deposition time (for spin-coating), optimum viscosity, and appropriate heat treatment after any deposition step result in a better catalytic activity for Pt/Nafion/GDL electrode. For chemically prepared samples, using $\mathrm{NaBH}_{4} \mathrm{OH}$ as a reducing agent, instead of sodium format and average deposition time of 30 minutes and heat treatment result in a better performance for the as-made electrodes. The benefits of heat are to remove any undesirable impurities resulting from early preparation stages. This allows a uniform dispersion and stable distribution of the catalyst and therefore improves the electrocatalytic activity of the synthesized catalyst [20] For Pt-based catalysts heat treatment also causes a more ordered structure.

Further, we found out that roughening had a positive effect on the performance of the Nafion membrane due to its effect on the porosity of the membrane.

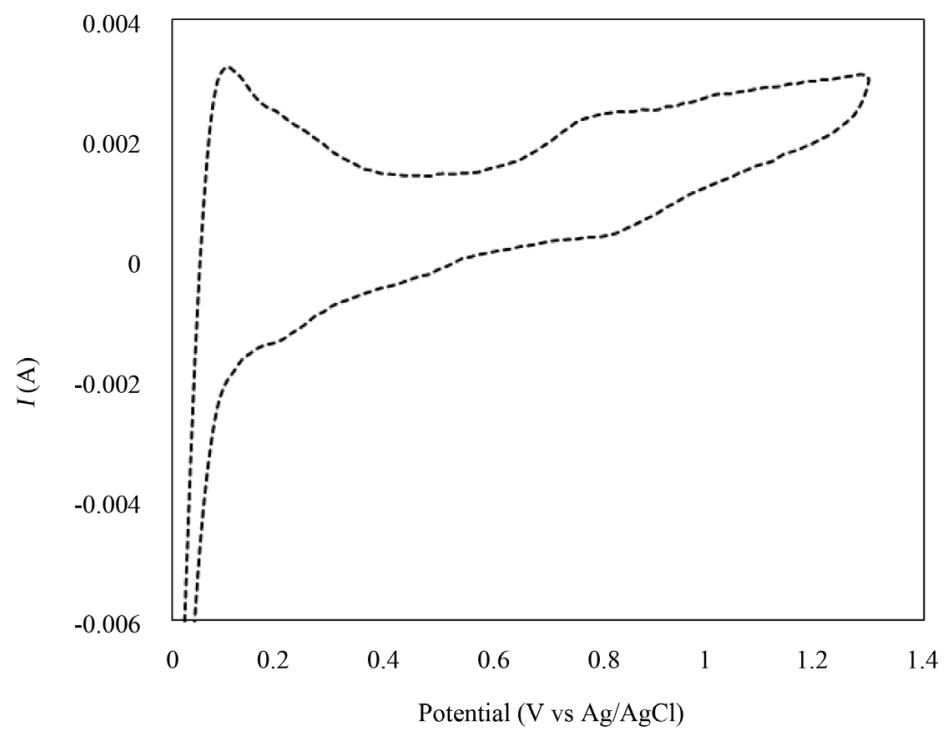

Figure 2. Cyclic voltammetry diagram of GDE3. 


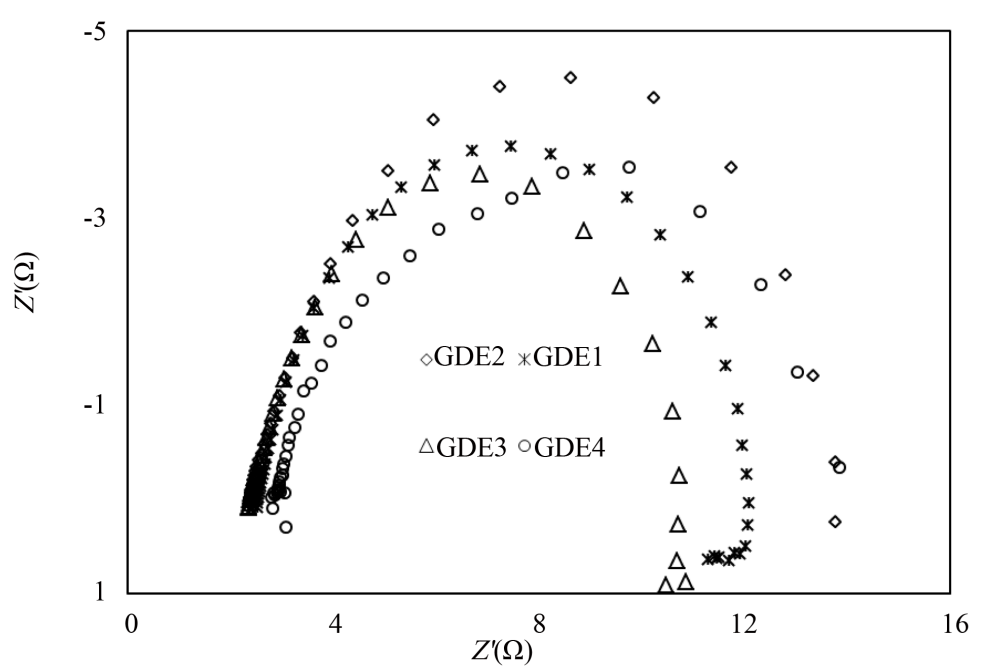

(a)

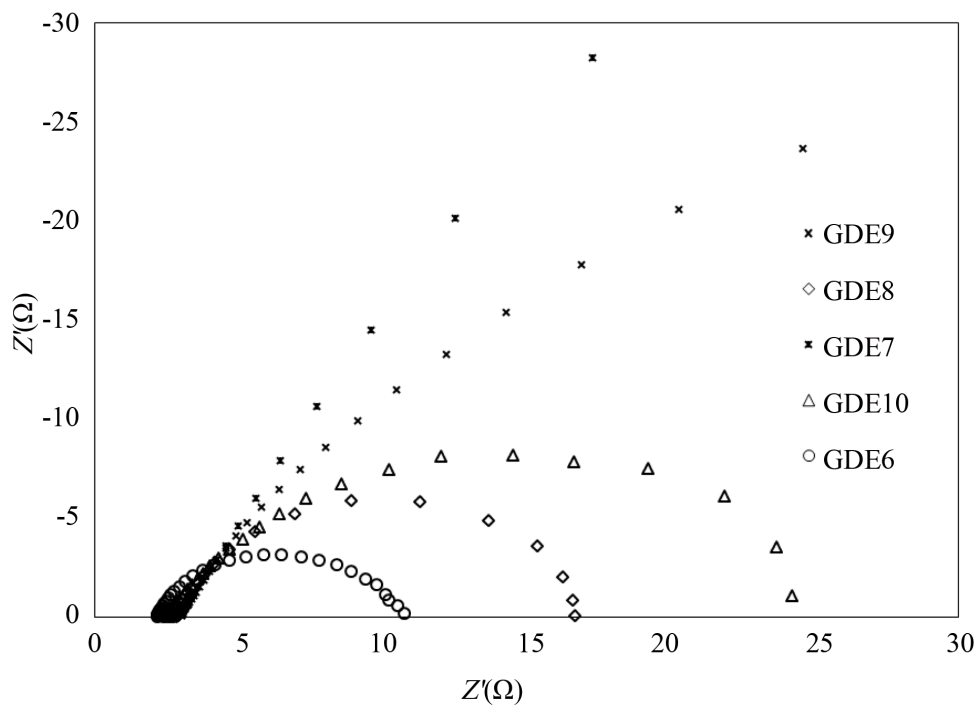

(b)

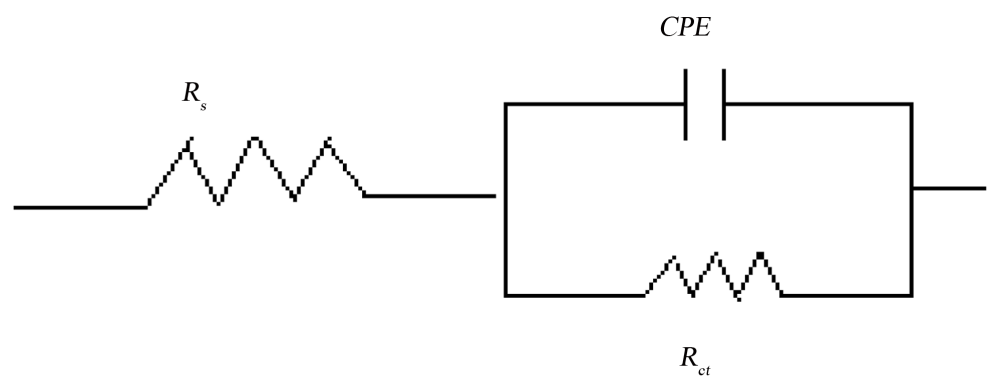

(c)

Figure 3. Nyquist plots of different electrodes.

X-ray diffraction (XRD) pattern of platinum coated Nafion membranes is shown in Figure 4. As shown, while GDE1 reveals only one crystal facet, GDE3 shows a poly crystalline Pt structure. Diffraction peaks at $39.5^{\circ}, 46^{\circ}$, $68^{\circ}$ and $82^{\circ}$ are attributed to $\mathrm{Pt}(111)$, (200), (220) and (311) crystalline facets respectively. The characteristic diffraction peaks of the face cantered cubic (fcc) structure demonstrate a successful platinum layer formation on the Nafion membrane. 


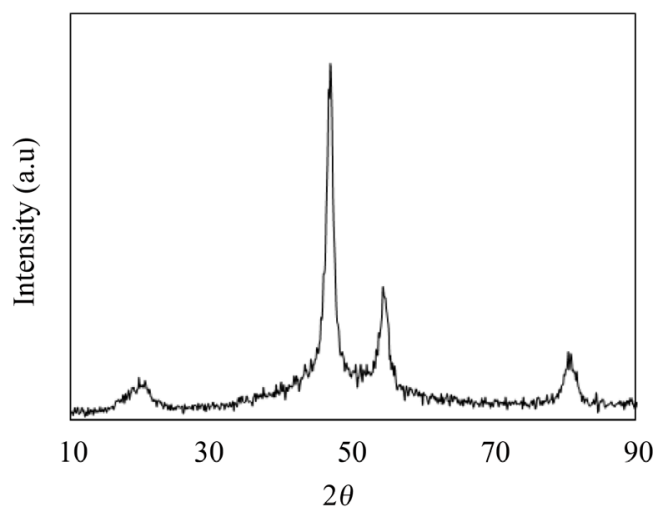

(a)

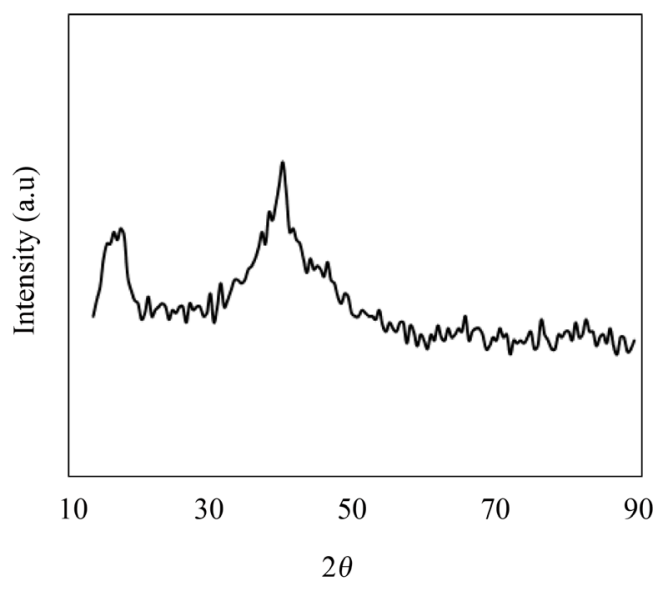

(b)

Figure 4. XRD pattern of GDE3.

Using Scherer equation, an average value of $3 \mathrm{~nm}$ was calculated as platinum particles size.

The particle size can be controlled by manipulating the synthesis temperature and procedure time. With the increase of temperature a smaller size can be prepared. [36] XRD diagrams of other electrodes show only Pt (111) crystal surface, and are similar to that of the GDE1. Different crystal facets have different activity toward ORR. Base on the electrochemical performance and XRD result, it is reasonable to conclude that polycrystalline platinum results in a better catalytic activity than the single crystal platinum coated Nafion membranes.

The morphology and elemental structure of Nafion/Pt/GDL electrodes were also examined by scanning electron microscopy (SEM). Figure 5 shows SEM images of different GDEs. As can be seen, thin and smooth platinum coating was formed. Scanning electron microscopic analyses indicate good adhesion between the metallic electrode and the Nafion polymer for most of the electrode. From Figure 5 it is obvious that the platinum particles are uniformly distributed on the membrane. These results confirm that both the sensitization and the activation of the membrane surface are uniform. Both GDE3 and GDE6 reveal very uniform platinum coating on the Nafion membrane .Non-optimized synthesis conditions, residual stress and Nafion membrane shrinking lead to the crack formation on the Platinum layer surface [37].

Figure 6 shows the energy-dispersive X-ray spectrometer (EDAX) result of the best prepared Pt-Nafion electrode. As shown, the atomic ratio of the platinum is $99.32 \%$ indicating a uniform platinum deposition on the Nafion membrane. There is no observable peak for $\mathrm{F}$ and $\mathrm{O}$, signifying they have been covered completely by platinum coatings. Additionally, a small amount of Palladium and Sn were detected, which is attributed to the activation process of the membrane.

\section{Conclusion}

Platinum-coated Nafion membranes were successfully synthesized by employing spin-coating and impregnation- 

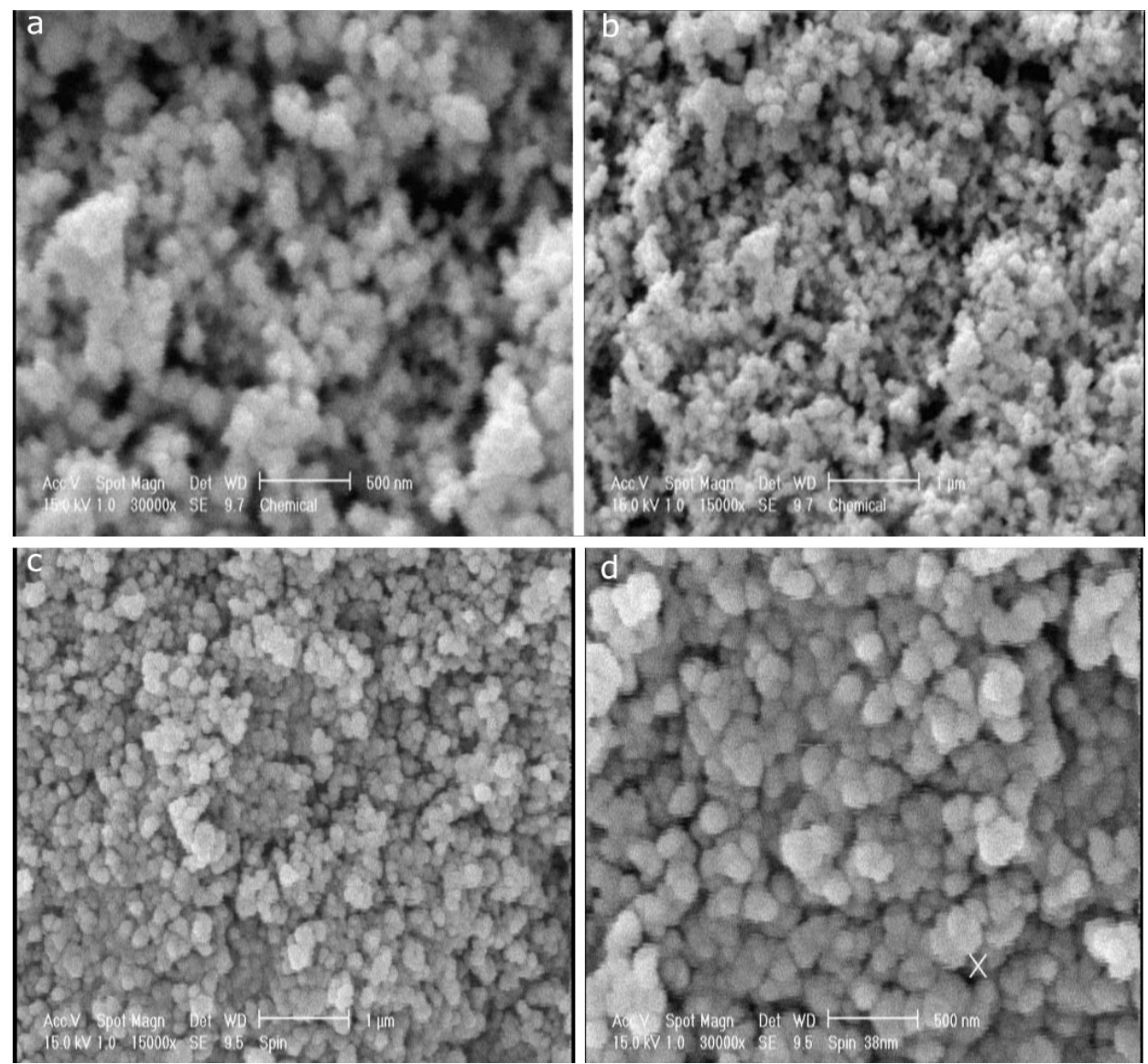

Figure 5. SEM images of (a): GDE1; (b): GDE2; (c): GDE3; (d): GDE6.

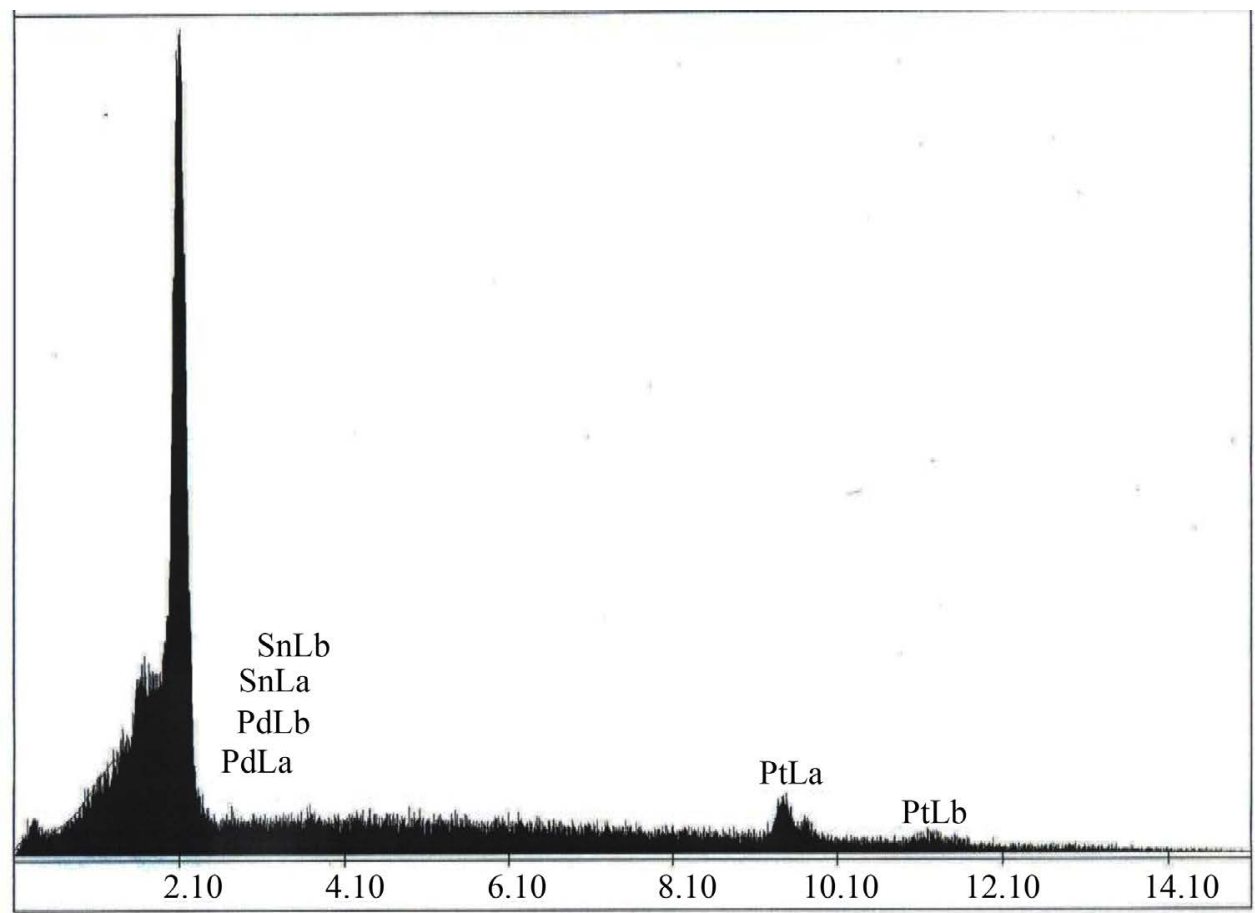

Figure 6. Energy dispersive X-ray spectrometer of GDE3. 
reduction methods. It was revealed that electrode performance was strongly affected by temperature, time, platinum concentration, reducing agent, speed rotation, and Nafion roughening. Platinum particles were dispersed uniformly on the Nafion membranes. Findings suggest that Nafion/Pt-GDL architecture is a promising way to synthesis electrode with a low loading of platinum catalyst. Given the main advantages of spin-coating method such as short time and easy deposition, this technique is a very useful tool for producing very low loading of platinum electrocatalyst with desired number of platinum layers.

\section{Acknowledgements}

Thanks to the Iran Renewable Energy Initiative Council for their financial support.

\section{References}

[1] Antolin, E. (2004) Recent Developments in Polymer Electrolyte Fuel Cell Electrodes. Journal of Applied Electrochemistry, 34, 563-576. http://dx.doi.org/10.1023/B:JACH.0000021923.67264.bb

[2] Rajalakshmi, N., Ryu, H. and Dhathathreyan, K.S. (2004) Platinum Catalysed Membranes for Proton Exchange Membrane Fuel Cells-Higher Performance. Chemical Engineering Journal, 102, 241-247. http://dx.doi.org/10.1016/j.cej.2004.05.004

[3] Son, D.H., Sharma, R.K., Shul, Y.G. and Kim, H. (2007) Preparation of Pt/zeolite-Nafion Composite Membranes for Self-Humidifying Polymer Electrolyte Fuel Cells. Journal of Power Sources, 165, 733-738. http://dx.doi.org/10.1016/j.jpowsour.2006.11.090

[4] Smitha, B., Sridhar, S. and Khan, A.A. (2005) Solid Polymer Electrolyte Membranes for Fuel Cell Applications. Journal of Membrane Science, 259, 10-26. http://dx.doi.org/10.1016/j.memsci.2005.01.035

[5] Zhang, J.J. (2008) PEM Fuel Cell Electrocatalysts and Catalyst Layers: Fundamentals and Applications. Springer, London. http://dx.doi.org/10.1007/978-1-84800-936-3

[6] Djilali, N. and Lu, D.M. (2002) Influence of Heat Transfer on Gas and Water Transport in Fuel Cells. International Journal of Thermal Sciences, 41, 29-40. http://dx.doi.org/10.1016/S1290-0729(01)01301-1

[7] Hawut, W. Hunsom M. and Pruksathorn, K. (2006) Platinum Electroless Deposition on Nafion Membrane for PEM Fuel Cells. Korean Journal of Chemical Engineering, 23, 555-559. http://dx.doi.org/10.1007/BF02706793

[8] Tsceng, K.I. and Yang, M.C. (2003) Platinum Electrodes Modified by Tin for Electrochemical CO Sensors. Journal of The Electrochemical Society, 150, H156-H160. http://dx.doi.org/10.1149/1.1576774

[9] Lister, S. and Mclean, G. (2004) PEM Fuel Cell Electrodes. Journal of Power Sources, 130, 61-76. http://dx.doi.org/10.1016/j.jpowsour.2003.12.055

[10] Zhang, S.S., Yuan., X.Z., Hin, J.N.C., Wang., H., Friedrich, K.A. and Schulze, M.A. (2009) A Review of PlatinumBased Catalyst Layer Degradation in Proton Exchange Membrane Fuel Cells. Journal of Power Sources, 194, 588-600. http://dx.doi.org/10.1016/j.jpowsour.2009.06.073

[11] Liang, Z.X. and Zhao, T.S. (2007) New DMFC Anode Structure Consisting of Platinum Nanowires Deposited into a Nafion Membrane. The Journal of Physical Chemistry C, 111, 8128-8134. http://dx.doi.org/10.1021/jp0711747

[12] Chou, J., Jayaraman, S., Ranasinghe, A.D., McFarland, E.W., Buratto, S.K. and Metiu, H. (2006) Efficient Electrocatalyst Utilization: Electrochemical Deposition of Pt Nanoparticles Using Nafion Membrane as a Template. The Journal of Physical Chemistry B, 110, 7119-7121. http://dx.doi.org/10.1021/jp054910k

[13] Zhao, D., Xi, B.L., Zhang, H.M. and Liu, M. (2010) The Effect of Platinum in a Nafion Membrane on the Durability of the Membrane under Fuel Cell Conditions. Journal of Power Sources, 195, 4606-4612. http://dx.doi.org/10.1016/j.jpowsour.2010.02.043

[14] Kim, Y.M., Park, K.W., Choi, J.H., Park, I.S. and Sung, Y.E. (2003) A Pd-Impregnated Nanocomposite Nafion Membrane for Use in High-Concentration Methanol Fuel in DMFC. Electrochemistry Communications, 5, 571-574. http://dx.doi.org/10.1016/S1388-2481(03)00130-9

[15] Díaz, R., Arbiol, J., Sanz, F., Cornet, A. and Morante, J.R. (2002) Electroless Addition of Platinum to SnO ${ }_{2}$ Nano- $^{-}$ powders. Chemistry of Materials, 14, 3277-3283. http://dx.doi.org/10.1021/cm011256m

[16] Sheppard, S., Campbell, S.A., Smith, J.R., Lloyd, G.W., Ralph, T.R. and Walsh, F.C. (1998) Electrochemical and Microscopic Characterization of Platinum-Coated Perfluorosulfonic Acid (Nafion 117) Materials. Analyst, 123, 19231929. http://dx.doi.org/10.1039/a803310b

[17] Bessarabov, D.G., Michaels, W. and Sanderson, R.D. (2000) Preparation and Characterisation of Chemically-Modified Perfluorinated Cation-Exchange Platinum-Containing Membranes. Journal of Membrane Science, 179, 221-229. http://dx.doi.org/10.1016/S0376-7388(00)00511-1 
[18] Cha, S.Y. and Lee, W.M. (1999) Performance of Proton Exchange Membrane Fuel Cell Electrodes Prepared by Direct Deposition of Ultrathin Platinum on the Membrane Surface. Journal of the Electrochemical Society, 146, 4055-4060. http://dx.doi.org/10.1149/1.1392591

[19] Bessarabov, D.G., Michaels, W. and Vermeulen, J.P. (1999) Electroless Deposition of Platinum on Proton-Conductive Perfluorinated Membranes Modified with Ethylene Diamine. Ionic, 5, 52-58. http://dx.doi.org/10.1007/bf02375903

[20] Ma, Z.Q., Cheng, P. and Zhao, T.S. (2003) A Palladium-Alloy Deposited Nafion Membrane for Direct Methanol Fuel Cells. Journal of Membrane Science, 215, 327-336. http://dx.doi.org/10.1016/S0376-7388(03)00026-7

[21] Fujiwara, N., Yasuda, K., Ioroi, T., Siroma, Z. and Miyazaki, Y. (2002) Preparation of Platinum-Ruthenium onto Solid Polymer Electrolyte Membrane and the Application to a DMFC Anode. Electrochimica Acta, 47, 4079-4084. http://dx.doi.org/10.1016/S0013-4686(02)00414-0

[22] Pethaiah, S.S., Kalaignan, G.P., Sasikumar, G. and Ulaganathan, M. (2011) Evaluation of Platinum Catalyzed MEAs for PEM Fuel Cell Applications. Solid State Ionics, 190, 88-92. http://dx.doi.org/10.1016/j.ssi.2011.03.013

[23] Chabi, S. and Kheirmand, M. (2011) Electrocatalysis of Oxygen Reduction Reaction on Nafion/Platinum/Gas Diffusion Layer Electrode for PEM Fuel Cell. Applied Surface Science, 257, 10408-10413. http://dx.doi.org/10.1016/j.apsusc.2011.06.104

[24] Jasinski, P., Molin, S., Gazda, M., Petrovsky, V. and Anderson, H.U. (2009) Applications of Spin Coating of Polymer Precursor and Slurry Suspensions for Solid Oxide Fuel Cell Fabrication. Journal of Power Sources, 194, 10-15. http://dx.doi.org/10.1016/j.jpowsour.2008.12.054

[25] Dellert, A., Schindler, K. and Roosen, A. (2009) Spin Coating of Hybrid Suspensions Using Infrared-Irradiation to Increase Layer Thickness. Thin Solid Films, 517, 4571-4575. http://dx.doi.org/10.1016/j.tsf.2009.01.006

[26] Pournaghi-Azar, M.H. and Biuck Habibi, A. (2005) Peparation of a Platinum Layer-Modified Aluminum Electrode by Electrochemical and Electroless Cemenations and Its Use for the Electrooxidation of Methanol. Journal of Electroanalytical Chemistry, 580, 23-34.

[27] Ludvigsson, M., Lindgren, J. and Tegenfeldt, J. (2000) Crystallinity in Cast Nafion. Journal of the Electrochemical Society, 147, 1303-1305. http://dx.doi.org/10.1149/1.1393354

[28] Siripong, M., Fredholm, S., Nguyen, Q.A., Shih, B., Itescu, J. and Stolk, J. (2000) A Cost-Effective Fabrication Method for Ionic Polymer-Metal Composites. MRS Proceedings, 889, 0889-W04-03.

[29] Lee, P.-C., et al. (2008) In Situ Formation of Platinum Nanoparticles in Nafion Recast Film for Catalyst-Incorporated Ion-Exchange Membrane in Fuel Cell Applications. Journal of Membrane Science, 332, 441-445. http://dx.doi.org/10.1016/j.memsci.2008.05.054

[30] Jordan, L.R., Shulka, A.K., Behrsing, T., Avery, N.R., Muddle, B.C. and Forsyth, M. (2000) Effect of Diffusion-Layer Morphology on the Performance of Polymer Electrolyte Fuel Cells Operating at Atmospheric Pressure. Journal of Applied Electrochemistry, 30, 641-646. http://dx.doi.org/10.1023/A:1004088402496

[31] Bezerra, C.W., et al. (2007) A Review of Heat-Treatment Effects on Activity and Stability of PEM Fuel Cell Catalysts for Oxygen Reduction Reaction. Journal of Power Sources, 173, 891-908. http://dx.doi.org/10.1016/j.jpowsour.2007.08.028

[32] Wang, H., Shi, Y. and Cai, N. (2013) Effects of Interface Roughness on a Liquid-Sb-Anode Solid Oxide Fuel Cell. International Journal of Hydrogen Energy, 38, 15379-15387. http://dx.doi.org/10.1016/j.ijhydene.2013.09.134

[33] Wang, X. and Hsing, I. (2002) Surfactant Stabilized Pt and Pt Alloy Electrocatalyst for Polymer Electrolyte Fuel Cells. Electrochimica Acta, 47, 2981-2987. http://dx.doi.org/10.1016/S0013-4686(02)00199-8

[34] Koslov, A.S., Palanisamy, T. and Narasimhan, D. (2002) Electroless Autocatalytic Platinum Plating. US Patent No. 6391477.

[35] Bennett, M.D. and Leo, D.J. (2003) Manufacture and Characterization of Ionic Polymer Transducers Employing Non-Precious Metal Electrodes. Smart Materials and Structures, 12, 424-436. http://dx.doi.org/10.1088/0964-1726/12/3/314

[36] Son, D.H., Sharma, R.K., Shul, Y.G. and Kim, H. (2007) Preparation of Pt/Zeolite-Nafion Composite Membranes for Self-Humidifying Polymer Electrolyte Fuel Cells. Journal of Power Sources, 165, 733-738. http://dx.doi.org/10.1016/j.jpowsour.2006.11.090

[37] Prabhuram, J., Zhao, T.S., Liang, Z.X., Yang, H. and Wong, C.W. (2005) Pd and Pd-Cu Alloy Deposited Nafion Membranes for Reduction of Methanol Crossover in Direct Methanol Fuel Cells. Journal of the Electrochemical Society, 152, A1390-A1397. http://dx.doi.org/10.1149/1.1926671 